\title{
Correction to: Disparities in the Treatment of Substance Use Disorders: Does Where You Live Matter?
}

\author{
Andrea Acevedo, PhD \\ Lee Panas, MS \\ Deborah Garnick, ScD \\ Dolores Acevedo-Garcia, PhD \\ Jennifer Miles, MA \\ Grant Ritter, PhD \\ Kevin Campbell, DrPH
}

\section{Correction to: J Behav Health Serv Res \\ https://doi.org/10.1007/s11414-018-9586-y}

The professional degree of co-author Kevin Campbell is incorrect. It should be "DrPH" and not "PhD".

Address correspondence to Andrea Acevedo, PhD, Institute for Behavioral Health, The Heller School for Social Policy and Management, Brandeis University, 415 South Street MS035, Waltham, MA 02453, USA.

Andrea Acevedo, PhD, Department of Community Health, Tufts University, 574 Boston, Avenue, Suite 208, Medford, MA 02155, USA.

Lee Panas, MS, Institute for Behavioral Health, The Heller School for Social Policy and Management, Brandeis University, Waltham, MA, USA.

Deborah Garnick, ScD, Institute for Behavioral Health, The Heller School for Social Policy and Management, Brandeis University, Waltham, MA, USA.

Jennifer Miles, MA, Institute for Behavioral Health, The Heller School for Social Policy and Management, Brandeis University, Waltham, MA, USA.

Grant Ritter, PhD, Institute for Behavioral Health, The Heller School for Social Policy and Management, Brandeis University, Waltham, MA, USA.

Dolores Acevedo-Garcia, PhD, Institute for Child Youth and Family Policy, The Heller School for Social Policy and Management, Brandeis University, Waltham, MA, USA.

Kevin Campbell, DrPH, Behavioral Health Administration, Washington State Department of Social and Health Services, P.O. Box 45330Olympia, WA, USA.

The online version of the original article can be found at https://doi.org/10.1007/s11414-018-9586-y

Journal of Behavioral Health Services \& Research, 2018. 187. (c) 2018 National Council for Behavioral Health. DOI 10.1007/s11414-018-9640-9 